\title{
PURIFICATION OF HIGH-QUALITY MICRO RNA FROM THE HEART TISSUE
}

\author{
Nóra Faragó, ${ }^{1}$ Ágnes Zvara, ${ }^{1}$ Z. Varga, ${ }^{2}$ P. Ferdinandy ${ }^{2,3}$ \\ and L. G. PUSKÁS ${ }^{1,4 *}$ \\ ${ }^{1}$ Laboratory for Functional Genomics, Institute of Genetics, Biological Research Center of the \\ Hungarian Academy of Sciences, Szeged, Hungary \\ ${ }^{2}$ Cardiovascular Research Group, Department of Biochemistry, University of Szeged, H-6720, \\ Szeged, Hungary \\ ${ }^{3}$ Pharmahungary Group, Szeged, Hungary \\ ${ }^{4}$ Avidin Ltd., Szeged, Hungary
}

(Received: January 18, 2011; accepted: February 9, 2011)

\begin{abstract}
Micro RNAs (miRNA) are an abundant class of small RNAs that regulate the stability and translation of cognate mRNAs. MiRNAs are potential diagnostic markers, moreover, they play an essential role in the development of various heart disesases. In case of limited tissue material, such as e.g. human biopsies, purification of miRNAs with sufficient yield is critical. Reproducible expression analysis of miRNAs is highly dependent on the quality of the RNA, which is often difficult to achieve from fibrous tissue such as the heart. Several companies developed general purification kits for miRNAs, however, none of them are specialized to fibrotic tissues. Here we describe an optimized miRNA purification protocol that results in high miRNA yield as compared to other methods including trizol-based and column-based protocols. By using our improved protocol, miRNA obtained from heart tissue gave more reproducible results in QRT-PCR analysis and obtained more significant calls (172 vs. 118) during DNA microarray analysis when compared to the commercially available kit. In addition to the heart tissue, the present protocol can be applied to other fibrotic tissues, such as lung or skeletal muscle to isolate high-purity miRNA.
\end{abstract}

Keywords: heart - microarray - miRNA expression - miRNA purification

\section{INTRODUCTION}

MiRNAs are small, noncoding RNAs typically act as negative regulators of the expression of protein-encoding genes $[1,2]$. Mature miRNAs target and bind to transcripts and interfere with their translation into protein. They cause either translational repression or mRNA degradation, depending on their degrees of complementarity or homology with target genes [17]. Generally, miRNAs are believed to cause translational repression due to partial pairing between miRNA and target mRNA.

Several reports have indicated that miRNAs play critical roles in essential biologic processes $[16,19,21]$. Each miRNA has a special capability to potentially regulate the expression of dozens of protein coding genes and thereby modulate several cellular pathways including those involved in differentiation, proliferation, apoptosis, and stress response [21]. Besides changes in the mRNA levels, down- or upregulation of miRNA expression in tissues have been correlated with several clini-

\footnotetext{
* Corresponding author; e-mail: pusi@brc.hu
} 
cally important diseases, for example cancer as well as cardiovascular, metabolic, and neurologic diseases $[3,8,11,20]$.

The first evidence of a potential role for miRNAs in cardiovascular diseases was the observation by van Roojid et al. in 2006 [18] showing that overexpression of stress-inducible miRNAs was sufficient to induce hypertrophy in cultured cardiomyocytes. Since then, several research groups have reported that miRNAs play an essential role in the development of cardiovascular diseases $[9,12,13]$. Accumulating evidence suggests that circulating miRNAs are promising stable biomarkers for diagnosis of different types of cancer and cardiovascular diseases [6, 7].

The storage and purification of miRNAs from samples are crucial for miRNA expression analysis. Because of the low molecular weight and low abundance of miRNA, their enrichment is an important step for the measurement of expression [15, 22]. By using total RNA to profile miRNA expression instead of purified miRNA can limit sensitivity because of the relative abundance of small RNAs in a total RNA sample [14]. Traditionally, miRNA purification relies on organic extraction followed by alcohol precipitation, however, much of the small RNAs are lost during this procedure. Several companies developed special purification kits for miRNAs that employ organic extraction followed by binding and purification of small RNAs on a silica fiber matrix. However, none of the commercially available kits are specialized to fibrotic tissues, such as the myocardial tissue. In case of limited quantity of tissue samples, e.g. human heart or lung biopsies, purification of miRNAs with sufficient yield is crucial. Reproducible expression analysis of miRNAs is highly dependent on the quality of the RNA, which is often difficult to achieve in fibrotic tissue samples.

Therefore, here we developed an optimized miRNA purification protocol for fibrous tissues that resulted in a significantly higher miRNA yield as compared to other methods in the literature. Moreover, miRNA obtained by our novel protocol gave more reproducible results in quantitative real-time PCR (QRT-PCR) analysis and more significant calls in DNA microarray analysis.

\section{MATERIALS AND METHODS}

\section{Total RNA purification by using the TRIZOL method}

Hearts were frozen and homogenized at the temperature of liquid nitrogen. To $50 \mathrm{mg}$ of homogenized tissue (rat and mouse hearts) $1 \mathrm{ml}$ TRIZOL reagent (Invitrogen) was added and incubated on room temperature for 5 minutes. After adding $200 \mu \mathrm{l}$ dichlormethane, samples were vortexed for 15 seconds, and incubated at room temperature for 3 minutes. Samples were centrifuged at $12,000 \times \mathrm{g}$ for 15 minutes at $4{ }^{\circ} \mathrm{C}$. Following centrifugation, the mixture separates into lower red, phenol-chloroform phase, an interphase, and a colorless upper aqueous phase. RNA remains exclusively in the aqueous phase. The upper aqueous phase was carefully transferred without disturbing the interphase into a fresh tube. To precipitate the RNA from the aqueous phase $500 \mu \mathrm{l}$ of isopropyl alcohol was added. After incubating the samples at $25{ }^{\circ} \mathrm{C}$ 
for 10 minutes they were centrifuged at $12,000 \times \mathrm{g}$ for 10 minutes at $4{ }^{\circ} \mathrm{C}$. The RNA pellet was washed with $750 \mu 175 \%$ ethanol twice.

RNA pellet was dried under vacuum for 5-10 minutes. RNA was dissolved in DEPC-treated water.

\section{Modified Trizol method for fibrotic tissues}

The same purification protocol was performed but because of the fibrotic nature of the heart samples, an additional Proteinase $\mathrm{K}$ digestion step was introduced. Homogenized heart tissue $(50 \mathrm{mg})$ was solubilized with a proteinase $\mathrm{K}$ buffer containing $120 \mu \mathrm{l}$ Paraffin Tissue Lysis Buffer (Roche, Germany), $20 \mu 1$ 10\% SDS and $50 \mu \mathrm{l}$ Proteinase K (Roche, Germany). Samples were incubated at $55^{\circ} \mathrm{C}$ for $30 \mathrm{~min}-$ utes. After adding $1 \mathrm{ml}$ TRIZOL reagent to the lysate the above mentioned protocol was followed.

\section{MiRNA purification by using the original protocol of the supplier}

After disruption of heart samples in liquid nitrogen, the sample was dissolved in a $20 \%$ Binding Buffer prepared from $80 \mu \mathrm{l}$ of Binding Buffer and $320 \mu \mathrm{l}$ of nuclease free water. All the other steps were done according to the Isolation of miRNA from Tissue protocol of the High Pure miRNA Isolation Kit (Roche, Cat. no. 05080576001). RNA was eluted from the second column by adding $100 \mu$ Elution Buffer.

\section{Improved miRNA isolation protocol for fibrotic tissues}

Our protocol is an improved version of the High Pure miRNA Isolation Kit (Roche, Cat. no. 05080576001) with inserting several additional steps into the standard protocol. Mouse or rat hearts were frozen and homogenized at the temperature of liquid nitrogen. To $50 \mathrm{mg}$ tissue powder $190 \mu \mathrm{l}$ proteinase $\mathrm{K}$ solution was added (prepared as follows: $120 \mu \mathrm{l}$ Paraffin Tissue Lysis Buffer (Roche, Germany), $20 \mu 1$ 10\% SDS and $50 \mu \mathrm{l}$ of $20 \mathrm{mg} / \mathrm{ml}$ Proteinase K (Roche, Cat. No. 03115879001). Samples were incubated at $55^{\circ} \mathrm{C}$ for 30 minutes. After incubation $325 \mu$ l Binding Buffer (Roche) and $320 \mu \mathrm{l}$ Binding Enhancer (Roche) was added and loaded onto the filter columns (Rohce). Next the filters were washed in two steps with 500 and $300 \mu 1$ of Washing Buffer (Roche) then the RNA was eluted by adding $40 \mu \mathrm{l}$ Elution Buffer (Roche). After this step the microcentrifuge tube contains the eluted miRNA as well as the total RNA. Next $310 \mu \mathrm{l}$ Binding Buffer was added to the eluate and the mixture was applied to a new filter tube. After a centrifuge step, the flow through was collected and $200 \mu \mathrm{l}$ of Binding Enhancer was added. The mixture was loaded into the upper reservoir of a new column. Followed by the two washing steps with 500 and $300 \mu \mathrm{l}$ of Washing Buffer, $40 \mu 155^{\circ} \mathrm{C}$ Elution Buffer was pipetted to the center of the col- 
umn membrane and incubated it for 2 minutes on room temperature before centrifugation. The eluates were collected and the quality and quantity was assessed spectrophotometrically (Nanodrop, USA) and with 2100 Bioanalyzer (Agilent). RNA samples were prepared according to the manufacturer's protocol and were loaded into the Eukaryote NanoChip (Agilent) and processed for 30 minutes. The RNA profile was automatically displayed as an individual electropherogram and as a gel-like image.

\section{Reverse Transcription, QRT-PCR}

The reverse transcription reaction was performed with the TaqMan ${ }^{\circledR}$ MicroRNA Reverse Transcription Kit (Applied Biosystems, United States, California). $350 \mathrm{ng}$ of miRNA (in the case of column-based kits) or $1000 \mathrm{ng}$ (in the case of Trizol-based purification) from each sample was reverse transcribed in the presence of 5X RT TaqMan ${ }^{\circledR}$ MicroRNA Assays (Applied Biosystems). $8 \mu \mathrm{l}$ reaction mixture contained $0.2 \mu \mathrm{l}$ dNTPs, $1.50 \mu \mathrm{l}$ MultiScribe ${ }^{\mathrm{TM}}$ Reverse Transcriptase (50 U/ $\left.\mu \mathrm{L}\right), 0.8 \mu 1$ 10X RT Buffer, $0.9 \mu \mathrm{l} \mathrm{MgCl}, 0.1 \mu \mathrm{l}$ RNase Inhibitor $(20 \mathrm{U} / \mu \mathrm{L}), 1.5 \mu \mathrm{l}$ XX RT primer and the template in a total volume of $3 \mu \mathrm{l}$. Reverse Transcription was carried out with the following cycling parameters in a thermocycler (Bioneer, Daedong, Korea): $16^{\circ} \mathrm{C}$ for 2 minutes, $42{ }^{\circ} \mathrm{C}$ for 1 minutes, $50{ }^{\circ} \mathrm{C}$ for 1 second, 45 cycles, then hold the samples on $85{ }^{\circ} \mathrm{C}$ for 5 minutes. After dilution with $64 \mu \mathrm{l}$ of water, $9 \mu$ l of the diluted reaction mix was used as template in QRT-PCR.

QRT-PCR was performed on a RotorGene 3000 instrument (Corbett Research, Sydney, Australia) with the TaqMan protocol [10]. A $20 \mu$ reaction mixture contained $10 \mu \mathrm{l}$ TaqMan ${ }^{\circledR}$ Universal PCR Master Mix (Applied Biosystems), $1 \mu$ of the TaqMan ${ }^{\circledR}$ MicroRNA Assays (Table 1) and $9 \mu$ of the diluted cDNA.

\section{MiRNA analysis by using DNA-microarrays}

A total of $50 \mathrm{ng}$ purified miRNA was labeled using Agilent's miRNA Complete Labeling and Hyb kit system (Agilent Technologies Palo Alto, CA, USA, p/n 51900456). The protocol was briefly the following: $25-25 \mathrm{ng}$ of two parallel samples were pooled together in a final volume of $2 \mu \mathrm{l}$ and subjected to a dephosphorylation reaction using Calf Intestinal Alkaline Phosphatase (CIP) at $37^{\circ} \mathrm{C}$ for 30 minutes in the final volume of $4 \mu \mathrm{l}$. In the second step, $2.8 \mu \mathrm{l}$ of DMSO was added to each sample for denaturation at $100{ }^{\circ} \mathrm{C}$ for 5 minutes and placed on ice immediately. Following this step, a ligation reaction was carried out using T4 RNA Ligase and Cyanine3-pCp in a total volume of $11.3 \mu \mathrm{l}$ for 2 hours at $16{ }^{\circ} \mathrm{C}$ to label the RNA samples. The labeled samples were completely vacuum dried on medium-high $\left(45^{\circ} \mathrm{C}\right)$ heat setting and hybridized onto the surface of Agilent $8 \times 15 \mathrm{k}$ Rat miRNA Microarray (Agilent Technologies, Palo Alto, CA, USA p/n G4473A). Dried and labeled samples were resuspended in $18 \mu \mathrm{l}$ of nuclease-free water and denaturated at $100{ }^{\circ} \mathrm{C}$ for 5 minutes in the presence of $1 \times$ Blocking Agent and 1× Hi-RPM Hybridization Buffer in a final 
Table 1

Purification efficiency (in $\mu \mathrm{g}$ ) of different protocols Standard deviation was determined from 4 independent runs and indicated in brackets after the average $\mathrm{Ct}$ values

\begin{tabular}{|l|c|}
\hline \multicolumn{1}{|c|}{ Method } & RNA yield \\
\hline Trizol & $15.36(4.30)^{*}$ \\
\hline Trizol + ProtK & $16.35(3.57)^{*}$ \\
\hline Roche & $1.72(0.76)$ \\
\hline Improved & $10.97(3.52)$ \\
\hline
\end{tabular}

*In case of Trizol purification RNA contains all RNA types (total, ribosomal and micro RNA).

volume of $45 \mu \mathrm{l}$ and immediately placed on ice. These mixes were used for the hybridization, which was done as previously described $[5,10]$. After hybridization the slides were washed in Gene Expression Wash buffer 1 containing Triton X-102 from Agilent Technologies at room temperature for 1 minute than in Gene Expression Wash buffer 2 containing Triton X-102 at $37{ }^{\circ} \mathrm{C}$ for another 1 minutes before scanning. Each array was scanned at $543 \mathrm{~nm}$ (for Cy3 labeling) in Agilent Scanner using the built-in XDR (Extended Dynamic Range) function with 5 um resolution. Output image analysis and feature extraction was done using Feature Extraction software of Agilent Technologies [4].

\section{RESULTS AND DISCUSSION}

\section{$M i R N A$ preparation, determination of the quality and quantity of the purified nucleic acids}

We optimized a miRNA purification protocol based on an existing kit which was originally developed for paraffin embedded tissue preparations, but was not appropriate for fibrotic tissues. The schematic representation of the improved purification workflow based on reagents from the High Pure miRNA Isolation Kit (Roche) is presented in Fig. 1.

We applied this improved approach to purify miRNAs from mouse and rat hearts. Using the same tissue as starting material we made total RNA purification with the traditional Trizol protocol, as well as Trizol protocol but inserting an extra step to proteolitically digest the muscle fibers with Proteinase $\mathrm{K}$ treatment. We also used silica-column based, commercially available miRNA purification kit from Roche as a control. After purification of miRNA or total RNA which contained miRNA the quantity of the purified nucleic acid was determined spectroscopically (Table 2). Although the total RNA yield for Trizol and our improved protocol resulted in similar amount, in case of Trizol purification methods RNA contains all RNA types (total, 


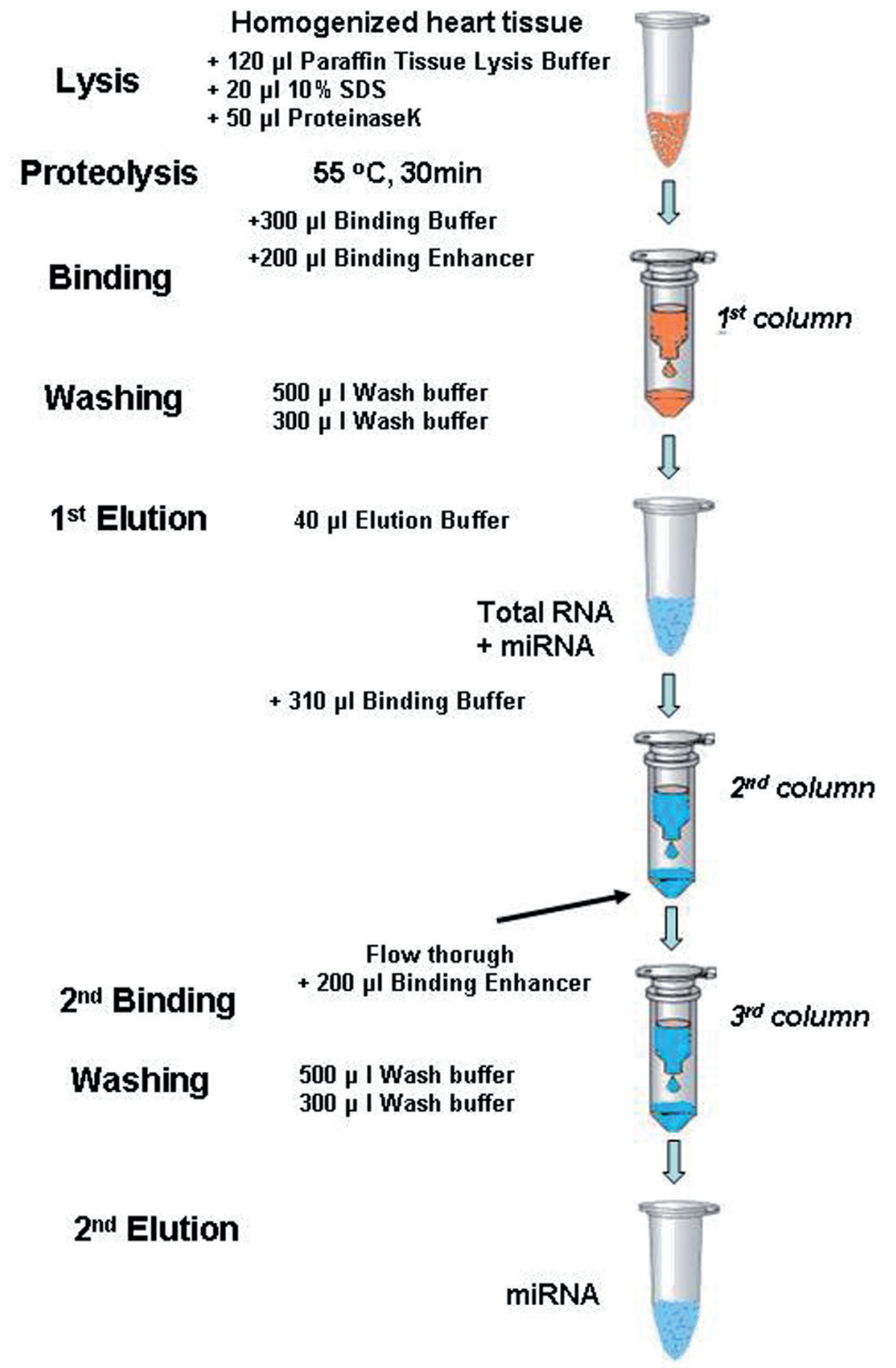

Fig. 1. Schematic representation of novel cardiac miRNA purification workflow 
Table 2

List of miRNAs analyzed in this study

\begin{tabular}{|l|l|l|}
\hline \multicolumn{1}{|c|}{ Name } & Assay ID & miRBase Accession \\
\hline hsa-miR-1 & 002222 & MIMAT0000416 \\
\hline hsa-miR-9 & 000583 & MIMAT0000441 \\
\hline hsa-miR-19a & 000395 & MIMAT0000073 \\
\hline hsa-miR-19b & 000396 & MIMAT0000074 \\
\hline hsa-miR-21 & 000397 & MIMAT0000418 \\
\hline hsa-miR-23b & 000400 & MIMAT0000418 \\
\hline hsa-miR-24 & 000402 & MIMAT0000080 \\
\hline
\end{tabular}

ribosomal and micro RNA). We found approximately six times more miRNA in the samples prepared by the improved protocol then in the samples obtained by standard purification kit from Roche.

The quality of the purified RNA was assessed by using BioAnalyzer chip (Agilent). The RNA profile of each sample was automatically displayed as an individual electrophoretogram and as a gel-like image. By using Trizol or Trizol+Proteinase K method total RNA was obtained having ribosomal RNA, messenger RNA and approximately $2-5 \%$ miRNA. When we compared the electrophoretogram results of the two column-based miRNA protocol (the Roche protocol and the improved one), we found high quality miRNA in the preparations without ribosomal and messenger RNA. However there was substantial difference in the quantity of the purified miRNAs obtained by different protocols. Based on the Bioanalyzer results we found at least six times more miRNA in the samples prepared by the improved protocol then in the samples obtained by standard purification kit (Fig. 2).

\section{QRT-PCR of seven miRNAs on templates prepared with different protocols}

We reverse transcribed RNA (total or miRNA enriched) obtained from mouse and rat hearts using four different protocols. In case of Trizol and Trizol+ Proteinase K protocols instead of using $350 \mathrm{ng}$ RNA we used $1000 \mathrm{ng}$ as template. Although we used higher amount of RNA obtained from the Trizol method no miRNA amplification could be detected. This can be explained by the non-efficient homogenization of the heart tissue. By using column-based technologies all miRNA (miR-1, miR-9, miR19a, miR-19b, miR-21, miR-23b, miR-24) could be successfully amplified. The TaqMan assays, used in this study to assess miRNA expression, are listed in Table 3. In each miRNA amplification experiments the improved protocol gave superior result over the samples obtained by the traditional or commercially available protocols. miRNA purification was also performed by using different kits from different ven- 

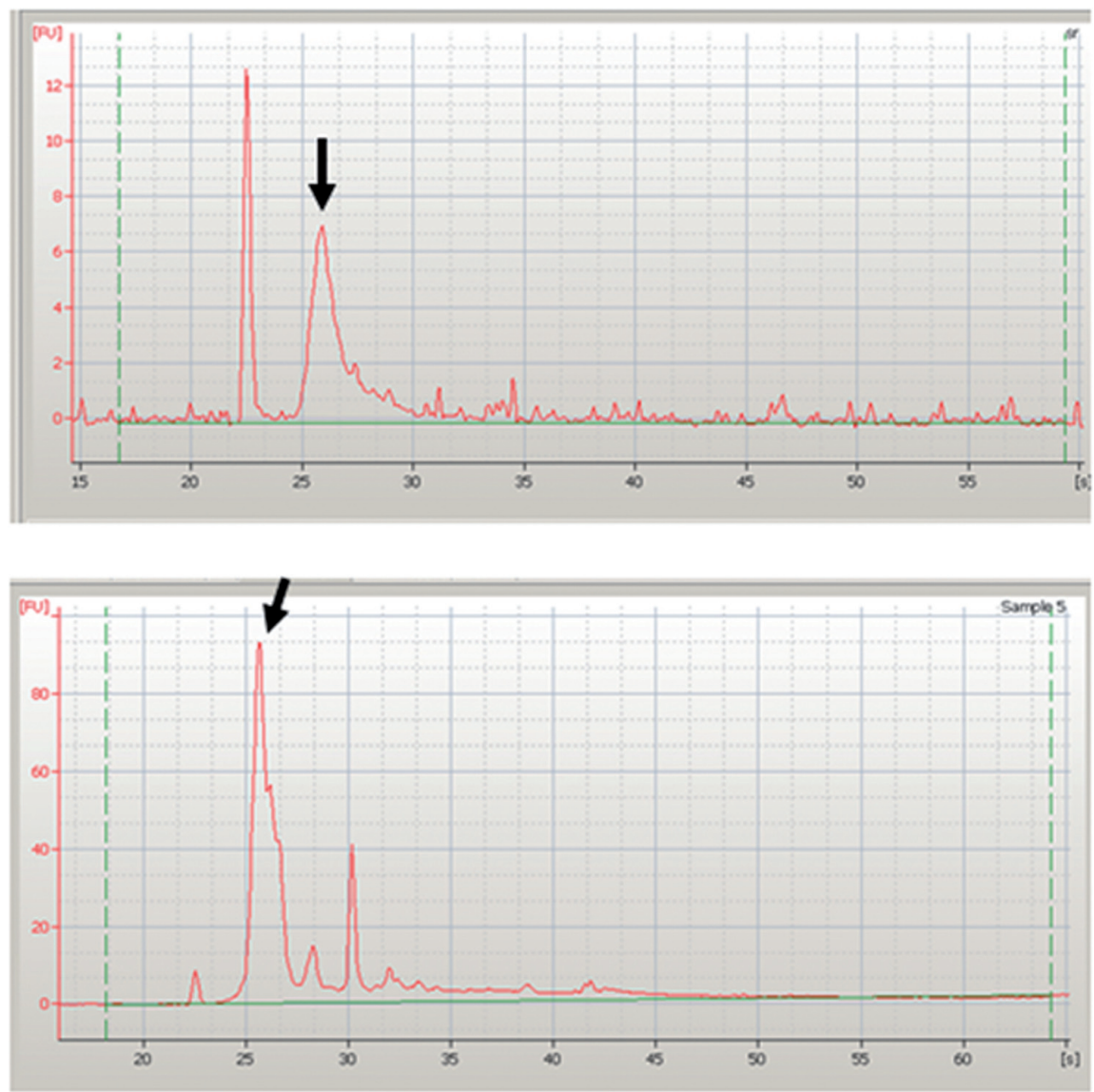

Fig. 2. Analysis of purified micro RNA with traditional (upper panel) and our improved protocol (lower panel) on Bioanalyzer. Arrows show micro RNA populations

dors, but none gave similar amplification efficiencies to our improved protocol (data not shown). In all miRNA genes tested other protocols in the QRT-PCR study resulted in higher $\mathrm{Ct}$ and standard deviation values then that of the improved protocol. Standard deviation was calculated from individual $\mathrm{Ct}$ values obtained from three independent QRT-PCR reactions (Table 3). Amplification curves of miR-9, miR-21 and miR-23b can be seen in Figure 3.

To determine total RNA content of the samples, which could contaminate the purified miRNA samples, we run two QRT-PCR reactions which were specific to cDNAs of coding genes (HPRT, GAPDH). Amplification was successful in the case of Trizolbased method and no amplification could be seen by using miRNA templates from the column-based methods (results are not shown). These results confirmed that the purified miRNA samples did not contain longer messenger RNAs. 


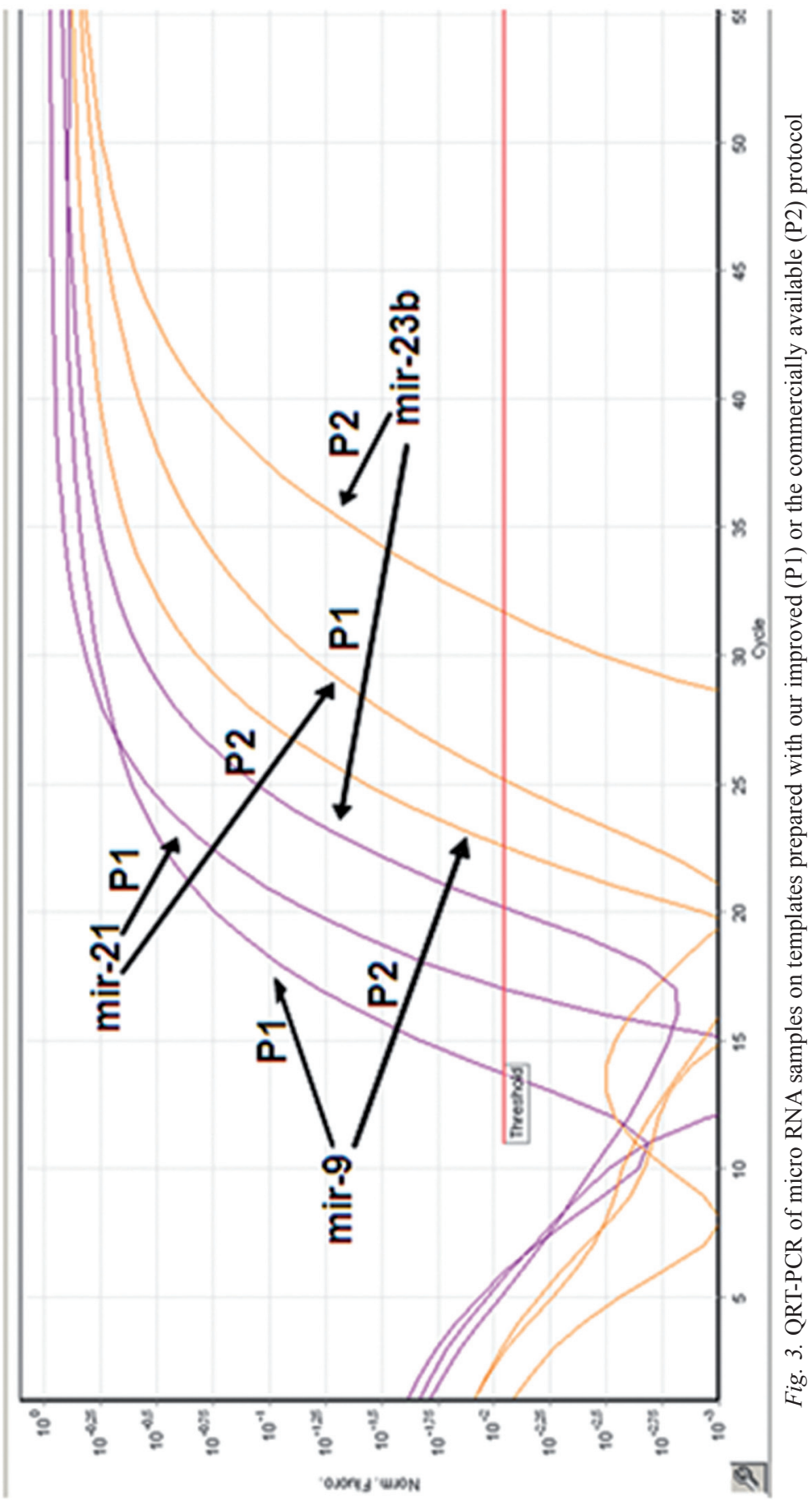

Acta Biologica Hungarica 62, 2011 
Table 3

Amplification efficiency of purified miRNA from mouse heart by using QRT-PCR

\begin{tabular}{|l|c|c|c|}
\hline \multicolumn{2}{|c|}{} & Average Ct & STDEV \\
\hline \multirow{3}{*}{ miR-1 } & Protocol 1 & 12.86 & 0.57 \\
\cline { 2 - 4 } & Protocol 2 & 17.84 & 1.96 \\
\hline \multirow{3}{*}{ miR-19a } & Protocol 1 & 21.05 & 1.67 \\
\cline { 2 - 4 } & Protocol 2 & 26.77 & 3.17 \\
\cline { 2 - 4 } & Protocol 1 & 18.98 & 0.56 \\
\hline \multirow{3}{*}{ miR-19b } & Protocol 2 & 21.55 & 0.93 \\
\hline \multirow{3}{*}{ miR-21 } & Protocol 1 & 15.16 & 0.55 \\
\cline { 2 - 4 } & Protocol 2 & 18.25 & 2.34 \\
\hline \multirow{3}{*}{ miR-23b } & Protocol 1 & 16.12 & 0.47 \\
\cline { 2 - 4 } & Protocol 2 & 20.41 & 2.87 \\
\cline { 2 - 4 } & Protocol 1 & 22.44 & 0.14 \\
\hline miR-24 & Protocol 2 & 27.09 & 5.03 \\
\cline { 2 - 4 } & Protocol 1 & 12.63 & 0.58 \\
\hline
\end{tabular}
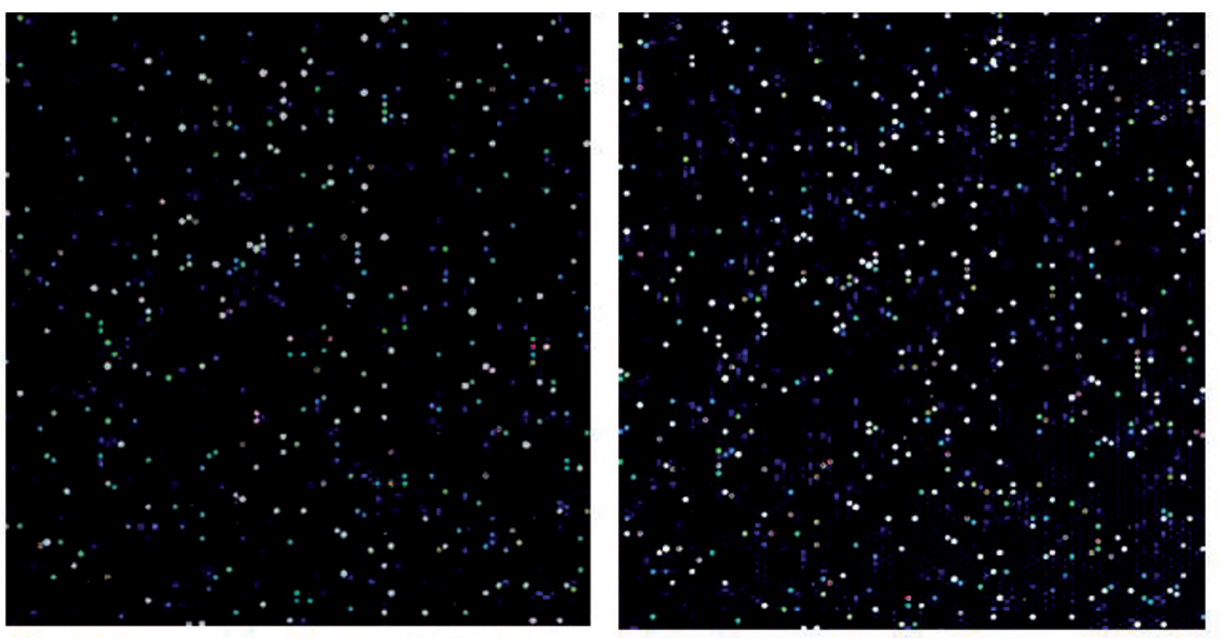

Fig. 4. Images after hybridization of micro RNAs prepared from traditional (left image) and our improved protocol (right image) on Agilent rat micro RNA microarrays 


\section{DNA-microarray analysis of miRNAs on templates prepared with different protocols}

To further test the quality of the purified miRNAs, fluorescent miRNA probes were prepared for DNA-microarray studies specific to miRNA profiling. The rat miRNA Agilent microarray contains probes for 350 miRNAs from the Sanger database v 10.1. As we could detect only tiny amount of miRNAs from Trizol methods, which gave unreliable results during QRT-PCR, we used only those miRNA samples that were derived from the column-based protocols.

After hybridizing the probes onto Agilent rat-specific miRNA DNA-microarrays, images were generated by confocal laser scanning of the microarrays. Part of the scanned images can be seen in Figure 4. From the images we could conclude that hybridization of miRNA from the optimized protocol resulted in more spots with higher intensities. After data analysis of the scanned images the expression of 172 miRNAs could be detected in the case of the improved protocol and only $118 \mathrm{miR}$ NAs with the traditional method.

\section{DISCUSSION}

The number of studies showing the role of miRNAs in cardiac pathologies including cardiac hypertrophy, fibrosis, arrhythmias, and ischemia/reperfusion injury is increasing rapidly. By using total RNA instead of purified miRNA to profile miRNA expression can limit sensitivity because of the relative abundance of small RNAs in a total RNA sample. Therefore, traditional RNA preparation protocols do not result in sensitive detection of small RNA expression. There are several commercially available approaches to enrich low molecular weight RNA from biological samples however most of the protocols result in very low yield when fibrotic tissue is the sample. Besides having poor yield, the quality of miRNA is much worse in comparison to preparations from non-fibrotic tissues according to our experience. To overcome this challenge, we have improved a protocol which is based on the Roche purification method which was developed for paraffin-embedded tissues.

The essence of our new method relies on efficient proteolytic digestion of fibrotic tissue, and a two-step purification protocol, which at first separate the total RNA including miRNAs, then on a new column miRNA is further purified by an additional elution. The schematic representation of the protocol can be seen in Figure 1. The superior quality of the purified miRNAs obtained by our modified protocol was compared to that produced by Trizol-based and commercially available kits.

We conclude, that our improved purification protocol, not only recovers high yields of miRNAs, but the resulting miRNA sample is more suitable for focused or global expression screening technologies, which can be achieved by QRT-PCR and/ or DNA-microarray experiments. 


\section{ACKNOWLEDGEMENTS}

This work was supported by the following grants: Ányos Jedlik "Avinomid", National Technology Project "Glinolid”, TÁMOP-4.2.2-08_1-2008-0013, and Baross DA-TECH-07-2008-0041.

\section{COMPETING INTERESTS STATEMENT}

The authors declare no competing interests.

\section{REFERENCES}

1. Ambros, V. (2004) The functions of animal microRNAs. Nature 431, 350-355.

2. Bartel, D. P. (2004) MicroRNAs: genomics, biogenesis, mechanism, and function. Cell 116, 281297.

3. Catalá, A., Zvara, A., Puskás, L. G., Kitajka, K. (2007) Melatonin-induced gene expression changes and its preventive effects on adriamycin-induced lipid peroxidation in rat liver. J. Pineal Res. 42, 43-49.

4. Davison, T. S. (2006) Analyzing micro-RNA expression using microarrays. Methods Enzymol. 411, $14-34$.

5. Faragó, N., Kocsis, G. F., Fehér, L. Z., Csont, T., Hackler, Jr. L., Varga-Orvos, Z., Csonka, Cs., Kelemen, J. Z., Ferdinandy, P., Puskás, L. G. (2008) J. Pharmacol. Toxicol. Methods 57, 145-154.

6. Gilad, S., Meiri, E., Yogev, Y., Benjamin, S., Lebanony, D., Yerushalmi, N. (2008) Serum microRNAs are promising novel biomarkers. PLoS ONE 3, e3148.

7. Ji, X., Takahashi, R., Hiura, Y., Hirokawa, G., Fukushima, Y., Iwai, N. (2009) Plasma miR-208 as a biomarker of myocardial injury. Clin. Chem. 55, 1944-1949.

8. Kloosterman, W. P., Plasterk, R. H. (2006) The diverse functions of microRNAs in animal development and disease. Dev. Cell 11, 441-450.

9. Lin, Y., Liu, X., Cheng, Y., Yang, J., Huo Y., Zhang, C. (2009) Involvement of MicroRNAs in hydrogen peroxide-mediated gene regulation and cellular injury response in vascular smooth muscle cells. J. Biol. Chem. 284, 7903-7913.

10. Puskás, L. G., Bereczki, E., Sántha, M., Vigh, L., Csanádi, G., Spener, F., Ferdinandy, P., Onochy, A., Kitajka, K. (2004) Cholesterol and cholesterol plus DHA diet-induced gene expression and fatty acid changes in mouse eye and brain. Biochimie 86, 817-824.

11. Puskas, L. G., Juhasz, F., Zvara, A., Hackler, Jr. L., Farid, N. R. (2005) Gene profiling identifies genes specific for well-differentiated epithelial thyroid tumors. Cell Mol. Biol. 51, 177-186.

12. Sayed, D., Hong, C., Chen, I. Y., Lypowy, J., Abdellatif, M. (2007) MicroRNAs play an essential role in the development of cardiac hypertrophy. Circ. Res. 100, 416-624.

13. Schroen, B., S. Heymans, S. (2009) MicroRNAs and beyond: the heart reveals its treasures. Hypertension 54, 1189-1194.

14. Shingara, J. (2005) An optimized isolation and labeling platform for accurate microRNA expression profiling. RNA 11, 1461-1470.

15. Small, E. M., Frost, R. J., Olson, E. N. (2010) MicroRNAs Add a New Dimension to Cardiovascular Disease. Circulation 121, 1022-1032.

16. Subramanian, S., Steer, C. J. (2010) MicroRNAs as gatekeepers of apoptosis. J. Cell Physiol. 223, 289-298.

17. Valencia-Sanchez, M. A., Liu, J., Hannon, G. J., Parker, R. (2006) Control of translation and mRNA degradation by miRNAs and siRNAs. Genes Dev. 20, 515-524.

18. Van Rooij, E., Sutherland, L. B., Liu, N., Williams, A. H., McAnally, J., Gerard, R. D., Richardson, J. A., Olson, E. N. (2006) A signature pattern of stress-responsive microRNAs that can evoke cardiac hypertrophy and heart failure. Proc. Natl. Acad. Sci. USA 103, 18255-18260. 
19. Vecchione, A., Croce, C. M. (2010) Apoptomirs: small molecules have gained the license to kill. Endocr. Relat. Cancer 17, F37-F50.

20. Weiler, J., Hunziker, J., Hall, J. (2006) Anti-miRNA oligonucleotides (AMOs): ammunition to target miRNAs implicated in human disease? Gene Ther. 13, 496-502.

21. Yanaihara, N., Caplen, N., Bowman, E., Seike, M., Kumanoto, K., Yi, M., Stephens, R. M., Okamoto, A., Yokota, J., Tanaka, T. (2006) Unique microRNA molecular profiles in lung cancer diagnosis and prognosis. Cancer Cell 9, 189-198.

22. Yin, J. Q., Zhao, R. C., Morris, K. V. (2008) Profiling microRNA expression with microarrays. Trends Biotechnol. 26, 70-76. 